\title{
Criteria and aspects of environmental journalism based on the materials of Kyrgyz authors' works
}

\author{
Nurjan Dzhumagazieva ${ }^{1, *}$ \\ ${ }^{1}$ Kyrgyz National University named after J. Balasagyn, Bishkek, Kyrgyzstan
}

\begin{abstract}
The article deals with the analysis of environmental problems from the point of view of aspects of publicistic creativity. In the modern period, the issues of preserving life on the planet have become a priority in the list of global world problems, as society stands on the verge of an environmental crisis. Environmental problems are interdisciplinary, but they are based on a sociocultural nature. The mass media and publicists are charged with the task of interpretation of the aspects of interaction between nature and society, the transformation of people's worldview in the aspect of the formation and development of ecological consciousness. Journalism and literature are able to form new meanings and new society's understanding of the importance of restoring harmony in the relationship "Human - Nature". The problem of environmental journalism is considered on the examples of works of the Kyrgyz authors: Ch. Aitmatov, M. Murataliev, K. Akmatova, A. Tokombayev. The presented material let us conclude that the problem of environmental journalism gains a new meaning in today's society and requires renewal of the scientific definition, which determines the scientific value of this article. The practical importance lies in the possibility of implementing the research results in the process of teaching at the faculties of journalism and philology in specialized and elective disciplines, as well as in the practice of mass media specializing in environmental themes.
\end{abstract}

\section{Introduction}

The problem of accurate and high-quality environmental information is being updated in the modern post-industrial society. Global geopolitical confrontation and changes in the main orientations of the world order have an impact not only on the political situation, but also on the sphere of natural resources, which become an instrument in the struggle for power in a particular region of the planet. In this regard, journalism and journalism are able to establish and develop environmental communication, which is based on the real relationship between man and nature, as well as on the reflection of social reality, public opinion about news events related to environmental problems. In addition, today each state must form new postulates of environmental policy that will allow society to survive in the conditions of the impending global environmental crisis. Kyrgyz journalism has a rich experience in understanding environmental issues, which allows us to systematize and generalize approaches and criteria for reflecting the environmental consciousness of society. In Kyrgyzstan, environmental

\footnotetext{
*Corresponding author: nnn330@yandex.ru
} 
issues are of paramount importance today. For example, it is well known that large-scale pollution of the pearl of Kyrgyzstan-the mountain lake Issyk-Kul, whose water has always had one of the highest levels of transparency and purity. Currently, the bottom of the lake is covered with a one-and-a-half meter layer of plastic bottles and other debris, which significantly worsens the ecology of one of the most healing lakes on the planet. The Kyrgyz media is actively writing about this fact, but the lake has not yet been cleared. It is obvious that in modern conditions, the solution of environmental problems is connected not only with the material base, but also with the reform of the old ecological thinking, which was limited to the usual statement of facts, without a deep analysis of causes and consequences. Today, it is necessary to transform an outdated form of thinking into a new "ecological paradigm" with its characteristic ecological consciousness. Because an innovative view of the existing problems in the relationship between man and the environment belongs to environmentalism. It consists in the fact that environmental problems are political and social problems, even to a certain extent ideological. In addition, the formation of a new "ecological paradigm" requires the formation of truly ecological thinking and action, and environmental concepts can play a significant role in this direction.

Environmentalism ( from the English environment - environment) is a philosophical and methodological approach in science and philosophy aimed at studying human-ecological relations and improving the quality of the human environment and all life on Earth. The key point of environmentalism is that it develops not only as a theory, but also as a certain communicative practice aimed at expanding the cognitive and praxeological field of human activity and forming an environmentally oriented "living policy" of society [1]. This means, as Cheng Manli writes, that the goal of environmentalism philosophy is to make the world more acceptable and suitable for human life and all life on Earth [2]. This, according to Giddens Entoni, is the difference between environmentalism and traditional social ecology [3].

The scientific community has always been interested in the past, present, and future of human-environmental relations. Steven Groarke notes that "the first attempts to understand environmental problems were made by representatives of ancient philosophy-Heraclitus, Protagoras, Democritus, Plato, Aristotle and Seneca" [4]. Problems of conservation and rational use of nature have become paramount for all types of theoretical and practical activities of people and are particularly acute in the sphere of ideology, which requires a radical change in the public perception of people and from this-the development of a new environmental behavior necessary for the preservation of life on Earth. Originated in the United States in the late nineteenth century, environmentalism spread mainly in Western countries and only in the late 80 's-early 90 's of the XX century reached the post-Soviet countries.

The request for environmental journalism became relevant at the end of the XX century, when the world began to worry about man-made disasters. Humanity believed that life on the planet could stop at any moment, and appropriate efforts should be made to prevent this. The main task of raising environmental awareness is assigned to the mass media. Uapiskij, O. N. writes ," however, scientists in various fields have also addressed these topics, trying to determine the criteria and goals of environmental consciousness" [5]. Each of the Sciences sociology, psychology, journalism, communication and PR - began to view its activities through the prism of environmental consciousness. It is obvious that the question of how modern journalism performs the important task of translating environmental discourse, what its achievements and unresolved problems are, is extremely relevant. The key note of environmentalism is the understanding that environmental problems are not just environmental problems. These are social problems in their content and origin. Therefore, the understanding of environmental problems and their solution depends on the study of the environmental consciousness of a particular society. Articles not only by writers and 
publicists such as Giddens E., Sutton F. [6], but also by scientists Porfireva I. D. [7], Bliznetskaya E. A., Vasilenko E. P. [8], Zh. Sadyraliyev [9], J. Montgomerie [10], Gergely Hegyi [11], Karabukaev Kadyrkul Sharsheevich [12], L. M. Kim \& at. [13], Gulmira M. Kasymalieva [14] different specialties are dedicated to the complex relationship between man and nature and the challenges facing journalism in their Reflection. In recent decades, problems arising from the interaction of society and the environment have become more and more urgent. There are sections in various Sciences that analyze various aspects of this interaction. For example, in sociology, within the framework of the corresponding direction, empirical material is intensively accumulated; both inductive generalizations of the local level and theoretical and methodological works on global processes have appeared. Thus, in environmental sociology, such concepts as" environmental alarm"," global ecological networks"," ecological-ecological movements"," socio-ecological catastrophes"," ecological modernization"," ecological consciousness"," ecological culture " and others are widely used. However, there are serious disagreements about their use. Terminological difficulties are connected, first, with the young age of the discipline, second, with the external influence of related Sciences that have their own reserves on the problems of interaction between the environment and society, and third, with the difference between the problems of foreign and domestic research. We need an expanded and comprehensive understanding of how we communicate with each other about the natural world and our relationship with it. How do people develop their beliefs and ideologies about the environment? How do we Express these beliefs through communication? How do the messages of social institutions affect us? And how do all these communications become part of the extended social structure of what we know as the "environment"? Communication with nature explores and explains the large levels of everyday communication that come together to form our understanding of the natural world; and examines all levels of communication, from communication at the individual level to messages generated by social institutions, including political and regulatory bodies, the media, and educational organizations. This refers to understanding the cultural context of the interaction between man and nature, and this context can only be provided by journalism. Thus, ecological consciousness sets a vector for understanding the problem situation and defines a set of views on environmental problems and ways to solve them. Ecological consciousness can be considered as one of the forms of social consciousness, reflecting the system of people's ideas about possible forms of relations and related links between society and the environment. Based on the above, the study of the research problem should be considered through the prism of the environmental consciousness of the Kyrgyz people.

M. Zh. Zhumagulov and N. S. Akmatova, "the rich and complex content of the form of protophilosophy of environmental awareness of the Kyrgyz nation as the core of the ordinary and traditional worldview of nomads, its pre-religious explications give a new meaning and import to wide variety spheres of human activity and express the measure of their ecologization in the development of world civilization. All noted above is explained by a special kind of ecological mentality, which is built on the principles of harmonious relationship with nature" [15]. Nomadic and wandering traditions of the Kyrgyz nation caused the specific interaction of human and nature not only in the ecological, but also in the historical, philosophical, moral and psychological awareness. We can even talk about a kind of "ecological mentality" [16] of the Kyrgyz nation, which provided a harmonious coexistence of natural world and human for centuries, and which is now inevitably destroyed. As noted by So, already in the "Manas" ancient Kyrgyz epos the topic of human's spiritual and moral attitude towards nature is one of the most important.

In the works of Kyrgyz authors, the problem of the unity of human and nature is not only informative, but carries a certain socio-historical content, which is transmitted through mythology, philosophical, religious ideas, etc. A human is a socialized natural creature, 
capable for actively creative productive work that has concrete-historical social forms and associates with the dynamics of affirming the most beautiful feeling of love. Moreover, love is associated with the primary need of a human to affirm his existence, in his unique individuality, in the free expression of will and at the same time as the affirmation of existence of the uniqueness of another and the need to know its essence. Ch. Aitmatov, as a great humanist of the $20^{\text {th }}$ and $21^{\text {th }}$ centuries, hopes for the natural essence of human, for his energy to rebirth through the creative attitude towards nature. However, Ch. Aitmatov showed himself the impossibility of this rebirth, that is, the return of human to his natural origin; in any case, he identified the tragedies associated with this spiritual process, for example, the image of grandfather Momun.

\section{Materials and methods}

The methodological basis of this article are comparative analysis methods.

\section{Results and discussion}

Nature in the environmentalism carries spiritual beginning, and it is even possible to find its connection with pantheism, panentheism, and hylozoism. But, on the other hand, there are also elements of atheism, as God is disappeared from this structural connection (Human Nature - Society) among the concepts of environment. That means, the nature is endowed with spirituality, morality, justice. It becomes the highest divine power. However, the human in the relations with this force has crossed all permissible limits, and now it threatens the human himself. Therefore, in the environmentalism, the question of protecting human from a powerful nature is also acute. This aspect suggests that the true essence of environmentalism is humanistical.

Scientist Zhumagulov, M.ZH., Akmatova, N.S. rightly notes that "the main objective of a writer is to show the eternal responsibility and duty of human towards nature."[17]. Artistic and philosophical understanding of the relationship between human and nature is one of the main directions and aspects of journalism of Ch. Aitmatov. In his works, the idea of the unity of human and nature develops from the simplest situations to the planetary scale, putting forward the idea of preserving nature, its exclusively moral and aesthetic significance for the subject. Through the examples of works "The White Ship", "The Day lasts longer than a Hundred Years", "The Scaffold", "Cassandra's Brand" etc., through an individual style of writing and evolution of the writer's creative work, it seems possible to convince oneself of the distinctive features of Aitmatov's creativity - it is the constant search for ideas of endless variety of human and nature relations, the unity of their destinies. The author tries to find a meaning of human life and each time finds it in accordance with the criteria by which a human relates to nature, tracing the moral, aesthetic, social conditionality of his actions. Nature acts as a special evaluation criterion of people's life and the knowledge of its laws it is an essential condition of human being, the basis of their rational existence. Such qualities as egoism, evil, unbridled greed, ignoring the interests of another person are shown in the images of Orozkul, Bazarbai . Isn't this a glaring example of the deepening disparity between morality and rationality, morality and reason, which has resulted in a situation where goodness and intelligence has been strengthened at opposite poles of human being? And the root of evil, whose name is environmental disaster, in the writer's view, is located not so much in people's not understanding of imminent danger, as in the spiritual degradation of humanity.

The works of the Kyrgyz prosaist M. Murataliev are devoted to the moral and aesthetic objectives and the problems of ecology. In the story "The Young Tynar" the author uses the 
methods of personification that came from the folklore and poetry of the akyns, as well as eastern literature (Attar, Navoi, Togolok Moldo). The author's task is to evaluate the moral qualities of a human, to contrast life positions of different people. At the end, the author uses an aposiopesis. The first meeting and action gives mixed feelings about the hero, and only step by step, through the relation to animals are expressed an essence of character, consumer attitude to nature. Chapter one tells about the free life of a bird and opposes the other nine chapters - life in captivity. The story is told from the point of view of animals and people. The narrator seems to dissolve into various images, reincarnate in one or the other, and at the same time has its own position. The conflict of the story is private, but such particular cases of disconnection from nature acquire a global sound. The author raises an actual problem of the relationship of human with the surrounding nature.

Moral and psychological problems of the relationship between nature and human were externalized in the story of M. Murataliev "The Men's games". It describes the national goat dragging game. When creating images of animals, the author uses a method of personification. The unity of the human and animal world is evidenced by the fact that people, in accordance with their character, behavior, and actions, receive associative animal names: "Saker falcon", "wolf-man", "vulture-man", and "leopard-man". The game shows the true essence of a human, the moral qualities of the players. The author uses a retardation technique that helps slow down the narration in rush of events, and gives time to comprehend all that's happening. Monologues and dialogues occupy an insignificant place in the story; the main psychologism lies in the assessment of events through the actions of the characters. So, the experienced hunter Zhakyn reasoned: "Why ever after such reliable protection of the forest, does a beast die at the hands of human? And beast's hearing is much sharper than human's, and eyes are sharper, and nose is excellent. It can also, having felt a danger, hide somewhere safe, hidden away. But no, - something pulls it to look at the human. But what? And why is it so trustful? Trust... That's what most often kills a beast. And maternal care for offspring. Risking their life, beasts often distract the hunter's attention to them, just to save their children...". The silent monologue of Zhakyn and of a dying leader of roe deers is illustrative of the cruel hunting of other hunters. "Suddenly the leader raised its beautiful horned head, looked at Zhakyp with a long look of sorrow, and said:

"If it weren't for you, I would never have let a man with a gun near my family. You taught me to trust. What for? To be killed by another? Did you really want it?"

Murataliev uses the method of personification in creating images of birds, foxes, camels, horses, giving them a human voice. The majestic wild roe deers, the maternal instinct partridges saving their chickens; young Tynar, Tynar's mother, a Tynar's father - all of them are masterfully transmitted by the author, once again confirming the harmony of the relationship between human and nature. In the end, Zhakyp did not shoot the roe deers and their leader, although he went hunting. It should be stressed, however, that the beauty of nature has a beneficial effect on the expression of moral feelings and generates sympathy, kindness, inspire love and benevolence for at least for a short time, makes a human cleaner and more noble.

The Kyrgyz writers, relying on the aesthetic traditions of national folklore, traditions of eastern literature, and achievements of Russian literature, reflected the changeable content of national life. The works of K. Malikov and A. Tokombayev [24] were the time of genesis, formation, and development of the novel genre in Kyrgyz literature. A. Tokombayev transmits spring in all its glory. "And it was spring again. The earth was clothed with the velvet of herbs, and fragrance of the blooming oleaster brought dreams of happiness. There are the trills of larks on the prairie, and the singers themselves fly up one second, fall like a stone to the ground the next. The ketmens of peasants gleam, reflecting the sun. It seems as if bound creatures nibble the earth with flat iron beaks"[24]. Tokombayev with masterly skill describes the Fergana gardens, coming pretty close all the colors: "It is summer. Gardens in 
Ferghana are melting under the sun. The strong branches of the apricot bend down from the weight of the fruit - as if they were gathered here, strung, preparing for a merry feast - the branches bow to the ground, arching as the horns of mountain goats. The overripe apricot under the tree darkens to the color of opium; a sharp sour smell rises from the ground, and stands in the air... And the powerful old poplar has outlived its time, its peers have a long time ago gone into the ground, and it still rustles its leaves, lonely. Poplar is lonely like a hundred year old patriarch - he has no companions, no peers left, and nobody knows how old it is on this earth. The young willows that crowd the old man, when blows little wind, respectfully bow down to the aksakal, like children before their forefather. And people, like young trees, used to bow down to the giant and even called it holy. "Who planted it here, why is it alone, where are its friends of the same age?" -so people asked themselves, and did not find an answer, and brought gifts to the old tree, and childless women slaughtered sacrificial sheep at its roots, begging the sky for a child"

The writer K. Akmatov also refers to the motives of nature in his creative work. In the novel "Earth Time", the basic events and conflict are built around the horses Marconi, Silach (Strongman) and Archa-Toru. The novel shows how the Kyrgyz people made a horse a standout among animals as holy and thought highly of it. "And now they are already walking on the ground among respectfully bloomed people. The Dolonotu residents of all people young and old know a lot about horses! They looked at the fairytale noble horses with silent admiration. And the horses seemed to feel like they were being admired. They walked slowly, moving their feet with indescribable grace, flared their nostrils, and passed theirs moist dark eyes".

Through the whole story goes the image of two mighty poplars - sacred poplars. "A symbol of the power of the great and eternal nature seemed to be two trees, in the shadow of which sheltered many travelers! Over time, the sacred poplars became a place of pilgrimage for the surrounding residents. People gathered here during the holidays, gathered in difficult and unfruitful years to pray together and to ask themselves for mercy from heaven. Poplars on such days were gaily decorated: colored rags were tied everywhere the hand could reach. The wind will come on, the leaves will flutter, the branches will shake, bright ribbons and rags will shudder, as if I send to the sky the aspirations and hopes of nomads who have settled among the mountains for a long time".

A deep awareness of one's own unity with nature, a desire to protect and preserve it for generations to come, is a red line. The writer introduces in the story the image of a Gray bird, whose voice is a voice of the Dolonotu residents, and is woven from songs and narrations, from the joys and sorrows of people. The place of sacred poplars becomes a recreation center for youth and residents. Because of revenge, the director Satylganov destroys Two Poplars, where he meets the Gray Bird protecting its nest. "He no longer thought about his victims the beautiful trees that for so many years decorated the foothills of Kungei Ala-Too and were the object of adoration for all Dolonatu. He also erased the Gray Bird from his memory. The fate of Satylganov is tragic; the Gray Bird follows him everywhere. "Wherever he goes, it follows him".

The transition to a new stage of civilization development imposes new requirements on the higher education system. The goal is to instill in students a love for their environment, to form students ' basic ideas about the modern system of ecology, to introduce into the educational process the disciplines and the essence of the natural limits of modern socioeconomic development. A graduate of a modern University must have a number of competencies, including environmental ones. Since today the Humanities and management specialties do not contain environmental disciplines, it is important to review the bachelor's program and, along with General cultural and professional competencies, form environmental ones. In a situation of conflict of interest in the field of environmental protection, graduates of technical specialties can talk about the problem from the "height" of 
their environmental competence (sometimes imaginary), in contrast to journalists, historians, psychologists, political scientists and philologists. As noted by Oreshkina T. A. "the system of environmental education should form an environmentally oriented person who is able to apply knowledge, skills, and personal qualities to solve the problems of professional activity, social participation, and personal success in the framework of sustainable development" [18]. The first stage of forming an environmentally oriented personality is the accumulation of knowledge about the system of human relations with the environment.for this purpose, it is necessary to include environmental disciplines in all educational programs of higher education. The second stage of the formation of ecological culture is the establishment of norms and patterns of human behavior in interaction with the environment in the course of their daily activities. This stage is impossible to pass speculatively, forming a new vector in each individual consciousness, the formation of patterns of environmental behavior is possible only in a step-by-step change in collective human activity. At the same time, there is no single fundamental solution for any environmental problem that must be implemented once and for all. In an uncertain future, the solution of environmental problems becomes a planned work on reflexive management of human activities in order to develop and implement solutions that will suit all interested parties, which is impossible without environmental education [18].

In the modern understanding of such scientists as S. Glazachev, V. Kosonozhkin, ecological culture is a culture of a new quality, in which the essential forces of a person, his spiritual and moral potential are realized, which harmonizes the relations of the soul, consciousness and being of a person. This is why the ideas of greening and humanizing all spheres and institutions of society: education, science, culture, law and government are so attractive. Moreover, when considering the categorical status of "ecological", ecological culture, which reflects the measure and method of realization of the essential forces of man in the socio-natural existence, the translation of the fullness of ecological culture in society and the individual, the formation of an integral worldview and world relations of man become the goal, value and meaning of education and pedagogical science. In a number of works ecological culture is justified as an immanent component of any educational system [19].

The authors note that the problem of spirituality in education is considered from an angle that allows us to go beyond the actual pedagogical methodology and make a socio-cultural transition to the analysis of the phenomenon of ecological culture. This transition makes it possible to see trends related to the orientation towards universal values and the greening of public consciousness. There is an awareness of the proximity of the concepts of "ecological culture" and "civilization". The very process of ecologization of life and society, the process of formation of ecological culture is selectedit reflects the modern high socio-cultural dynamics and is generated by self-development, self-organization of the spiritual life of society [19].

The authors identify the basic (universal, intraprofessional) systems of environmental competencies that reveal important aspects of the most complex concept of "environmental culture of the individual", which can be represented as follows:

* Has the ability to treat the natural environment responsibly based on the recognition of its universal value.

* Understands the essence of the natural limits of modern socio-economic development and the causes of the environmental crisis.

* Is able to evaluate the results and consequences of its activities from the point of view of natureoбраости stability (biospheric compatibility), not causing or minimizing harm to nature.

* Has the skills of natural activity and behavior.

* Is able to perceive emotionally and sensually the threat of destruction of the natural environment, to show the will to protect and protect it. 
* Has a need for activities in the field of ecology and nature management.

* Has a sense of nature, is able to perceive its greatness and beauty.

* Has a need to communicate with nature, being in natural landscapes.

* It has a holistic Outlook and attitude to the world [19].

\section{Conclusions}

In such a way, it may be noted that for Kyrgyz journalism and literature, the oral-poetic and socio-ethical understanding of careful attitude towards nature has been developed for centuries. Each subsequent poet or thinker, based on the daily experience and lifestyle of the ethnic group, expands and deepens the boundaries and scope of the old worldview. The main criteria and aspects of environmental journalism based on the examples of the works of Kyrgyz authors considered in this article include the following:

1. Connection with the nomadic culture of the Kyrgyz nation, where nature is endowed with divine, spiritual power;

2. Appeal to the archetypes of the Kyrgyz environmental awareness, in which there is the inevitability of punishment for the barbaric attitude towards nature;

3. Using the technique of personification of natural phenomena and animals to enhance the emotional impact on a reader;

4. Philosophical understanding of the unity of human and nature as a new paradigm of environmental awareness;

5. The need for effective participation in the nature conservation and a sensitive attitude towards all life on the planet as a part of the universe and world harmony;

6. Formation of environmental competencies in higher educational institutions of Kyrgyzstan.

On the basis of the considered examples the author suggests to formulate a definition of environmental journalism as follows: "Environmental journalism is a kind of literary or journalistic creativity, which is based on socio-cultural and moral understanding of environmental awareness, aimed at preserving the harmonious unity of nature and human."

Further study of environmental journalism is relevant from viewpoint of its global significance, as well as in the aspect of forming public opinion in the issues of environment protection. This research provides an opportunity for teachers of journalism faculties to teach students how to compose texts and longreads on environmental themes, taking into account the criteria of environmental journalism, and allows media employees to concentrate their creative efforts in the specific contexts of environmental protection and the formation of a new environmental awareness of society.

\section{References}

1. United Nations. Environmental Performance Reviews: Kyrgyzstan (2010) DOI: https://doi.org/10.18356/b6bfc6a5-en

2. Cheng Manli, Procedia - Social and Behavioral Sciences 2(5), 7486-7490 (2010) doi:10.1016/j.sbspro.2010.05.114

3. E. Giddens, Sotsiologiya (Yeditorial URSS, M., 2005) ISBN 5-354-01093 doi: 10.17323/978-5-7598-1525-9

4. S. Groarke, Behavioral Sciences, Social Sciences 264 https://doi.org/10.4324/9781315880150

5. O.N. Yanickij, Ekologicheskaya kultura: ocherki vzaimodejstviya nauki i praktiki (Nauka, M., 2007) ISBN 5-02-035371-X11 
6. E. Giddens, F. Sutton, Basic concepts in sociology (M.: Publishing. House of the Higher School of Economics, 2018) ISBN 978-5-7598-1525-9 doi: 10.17323/978-5-7598-15259

7. I.D. Porfireva, Politicheskiye nauki.: International research journal 03(57) (2017) DOI: https://doi.org/10.23670/IRJ.2017.57.086

8. E.A. Bliznetskaya, E.P. Vasilenko, MGIMO Review of International Relations 5(62), 131-145 (2018) https://doi.org/10.24833/2071-8160-2018-5-62-131-145

9. Zh. Sadyraliyev, Vestnik PNIPU. Sotsialno-ekonomicheskiye nauki 4 (2018) DOI: 10.15593/2224-9354/2018.4.29

10. J. Montgomerie, Critical Methods in Political and Cultural Economy (Routledge, New York, NY, 2017) https://doi.org/10.4324/9781315677811

11. G. Hegyi, L. Zsolt Garamszegi, and M. Eens, Behavioral Ecology 19(6), 1208-1216 (2008) https://doi.org/10.1093/beheco/arn085

12. K. Karabukaev, Society: philosophy, history, culture (2017) https://doi.org/10.24158/fik.2017.10.3

13. L.M. Kim, A.M. Muhitdenova, A.A. Kamaldinova, Sh. Khalikova, Procedia - Social and Behavioral Sciences 14022, 687-690 (2014) doi: 10.1016/j.sbspro.2014.04.495

14. G.M. Kasymalieva, Culture in the Eurasian space: traditions and innovations 1(2), 2529 (2018) DOI: 10.32340/2541-772X-2018-1-25-30

15. M.Z. Zhumagulov, N.S. Akmatova, Vestnik KarGU (2013) https://articlekz.com/article/7918

16. E. Freedman, Applied Environmental Education \& Communication 10(2), 126-134 (2011) DOI: 10.1080/1533015X.2011.577378

17. M.Z. Zhumagulov, N.S. Akmatova, Vestnik KarGU (2013) https://articlekz.com/article/7918

18. T.A. Oreshkina, Vestnik instituta sotziologii 8(4), 113-123 (2017) DOI: https://doi.org/10.19181/vis.2017.23.4.484

19. S. Glazachev, V. Kosonozhkin, EPNI " Bulletin of the International Academy of $\begin{array}{lllll}\text { Sciences. } & \text { Russian } & \text { section" } & \text { 1, } & \text { (2012) }\end{array}$ http://www.heraldrsias.ru/online/2012/1/222/ 